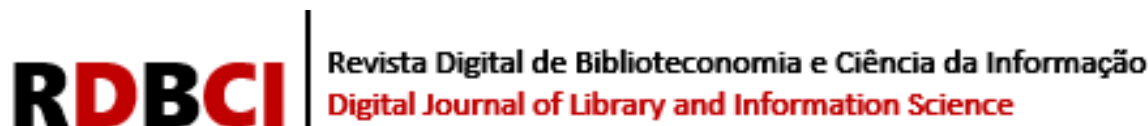
ISM
d.
10.20396/rdbci.v19ioo.8667482
(c) (i) BY

ARTIGO

\section{Metadados e padrão de metadados para editoras universitárias brasileiras}

\author{
Fátima Beatriz Manieiro do Amaral ${ }^{1}$ (iD) https://orcid.org/0000-0003-3703-0644 \\ Ana Carolina Simionato Arakaki 2 iD https://orcid.org/0000-0002-0140-9110 \\ Ariadne Chloe Mary Furnival ${ }^{3}$ iD https://orcid.org/0000-0002-2344-4400 \\ ${ }^{1}$ Universidade Federal de São Carlos, São Carlos, SP, Brasil / e-mail: fatima.mdoamaral@gmail.com \\ 2 Universidade Federal de São Carlos, São Carlos, SP, Brasil / e-mail: acsimionato@ufscar.br \\ 3 Universidade Federal de São Carlos, São Carlos, SP, Brasil / e-mail: chloe@ufscar.br
}

\begin{abstract}
RESUMO
Introdução: As editoras universitárias constituem um campo cultural relacionado à comunicação e divulgação científica. Por meio de discussões da área de Ciência da Informação, com a utilização das Tecnologias da Informação e Comunicação e de metadados, o contexto se torna pauta a fim de que os livros publicados sejam recuperáveis, isto é, encontráveis e acessíveis na Web. Sendo assim, pretende-se elaborar uma discussão sobre os benefícios da adoção de um padrão de metadados por editoras universitárias e a apresentação do ONIX for Books, padrão de metadados editoriais utilizado globalmente. Método: Este trabalho consiste em uma pesquisa exploratória, realizada a partir de um levantamento bibliográfico - com fontes obtidas na busca pelos termos "metadados" e "editoras universitárias brasileiras" no operador Google Acadêmico e na BRAPCI - e documental- com as pesquisas nos websites das editoras universitárias e do padrão ONIX. Resultados: Verificou-se na literatura a importância e benefícios da adoção de um padrão de metadados para a representação de recursos informacionais, com destaque para o ONIX for Books já que é um padrão rico e amplamente adotado nacional e internacionalmente. Conclusão: Para as editoras universitárias, utilizar um padrão de metadados para a descrição de seus livros ou recursos informacionais é urgente, uma vez que garantem a interoperabilidade e recuperação por lojas em plataformas digitais, bibliotecas e bases de dados, chegando mais facilmente ao usuário-cliente final.
\end{abstract}

PALAVRAS-CHAVE

Livros eletrônicos. Metadados. Editoras universitárias. Acesso livre.

\section{Metadata and metadata standardization for Brazilian university press}

\begin{abstract}
Introduction: University publishing presses constitute a cultural field related to scientific communication and dissemination. By means of discussions in the field of Information Science, and with the use of Information and Communication Technologies and metadata, this context becomes the backdrop so that published books are retrievable, that is, findable and accessible on the Web. The aim of this article, therefore, is to discuss the benefits of university presses in adopting a metadata standard, as well as to present ONIX for Books, an editorial metadata standard used globally. Methods: This work presents exploratory research, carried out by means of a bibliographic review based on resources obtained from using the search terms - in Google Scholar and the BRAPCI database "metadata" and "Brazilian university presses". A documentary review was carried out via searches on university press
\end{abstract}




\section{RDBCI}

websites, as well as on the official website for the ONIX standard. Results: The literature showed the importance and benefits of adopting a metadata standard for the representation of information resources, with emphasis on ONIX for Books, given that it is a rich standard widely adopted nationally and internationally. Conclusion: For university presses, using a metadata standard for the description of their books or information resources is urgent, as they ensure interoperability and recovery through digital platforms, virtual stores, libraries and databases, thereby reaching the end user-customer more easily.

Electronic books. Metadata. University press. Open access.

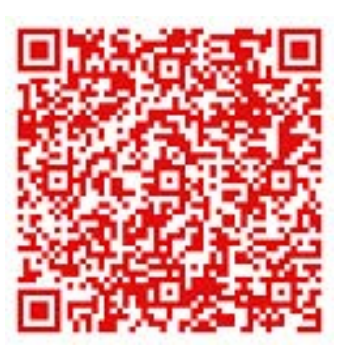

JITA: HO. e-books. 


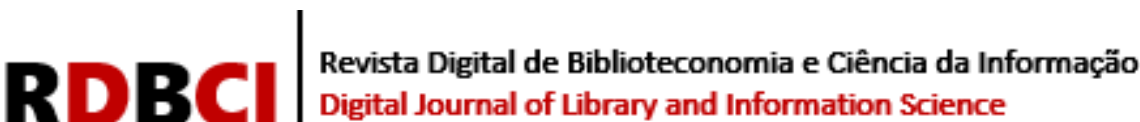

\section{INTRODUÇÃO}

Com a expansão e desenvolvimento das Tecnologias da Informação e Comunicação (TIC), as editoras universitárias vêm atualizando suas políticas e práticas editoriais para atender às novas necessidades dos usuários por recursos informacionais técnicos e científicos, foco de trabalho dessas instituições. Com os mecanismos de buscas, como o Google, os usuários almejam respostas mais rápidas e precisas para suas necessidades de informação. Atender tais demandas só é possível se os sistemas de buscas conseguirem recuperar a informação e isto não é viável se os metadados dos recursos informacionais não estiverem devidamente descritos, padronizados e estruturados.

Segundo Alves (2018), editores e livreiros enfrentam dificuldades em relação aos metadados, pois os fornecem em padrões próprios ou de acordo com padrões dos livreiros. Como consequência "Esse processo pode acarretar em erros na distribuição dessas representações, demora na publicação do recurso publicado e, portanto, demora no início das vendas” (ALVES, 2018, p. 240). A autora ainda acrescenta que o surgimento de padrões de metadados pelas editoras diminuem esses desafios já que garantem uma padronização nas representações das publicações impressas e digitais, possibilitam a interoperabilidade dos dados de maneira mais eficiente entre as editoras, livrarias, distribuidoras, atacadistas, na Web e em outros domínios.

ONIX for Books Product Information Format é um padrão internacional para representação e compartilhamento de dados bibliográficos de livros impressos ou digitais. $\mathrm{O}$ ONIX for Books permite que os editores façam o gerenciamento de grandes volumes de metadados enriquecidos com distribuidores ou lojas varejistas, de maneira automatizada e sem ambiguidades. É um padrão de metadados rico e garante o compartilhamento de dados e informações altamente estruturadas e padronizadas.

O ONIX é utilizado pela SciELO Livros para se interoperar com outras plataformas. Além disso, os serviços específicos de distribuição de metadados disponíveis no Brasil (MercadoEditorial.org e Metabooks) também utilizam o padrão ONIX. A partir da aproximação com o contexto de atuação das editoras universitárias brasileiras, percebeu-se no levantamento bibliográfico a falta de uma descrição mais clara e objetiva que levasse aos interessados uma visão mais profunda do padrão ONIX for Books. Como afirma Alves (2018, p. 239), "O padrão não é tão conhecido e utilizado no Brasil”.

Considerando o contexto descrito acima, o objetivo deste trabalho é descrever o padrão ONIX for Books, relacionado ao campo de atuação das editoras universitárias brasileiras e caracterizando o conceito de metadados. Para tal, foi realizada uma pesquisa exploratória, que, de acordo com Gonsalves (2007, p.67), "se caracteriza pelo desenvolvimento e esclarecimento de ideias, com o objetivo de oferecer uma visão panorâmica, uma primeira aproximação a um determinado fenômeno que é pouco explorado"; e descritiva, porque visa "escrever as características de um objeto de estudo" (GONSALVES, 2007, p. 67). Durante o levantamento bibliográfico e documental, os procedimentos de coleta de dados utilizados para se chegar às fontes de informação, foram captadas durante o primeiro semestre de 2021. Buscando uma visão abrangente da bibliografia internacional, utilizou-se o Google Acadêmico como base para a busca de livros que conceituassem sobre metadados no campo da Ciência da Informação (CI) por meio do termo em inglês (metadata) central no desenvolvimento deste trabalho. Considerando o contexto de produção científica da CI no Brasil, utilizou-se o termo em português, "metadados", para uma busca na base BRAPCI. No Google Acadêmico, o termo "editoras universitárias brasileiras" recuperou resultados essenciais sobre pesquisas no âmbito destas instituições. Para a busca documental, optou-se pela coleta de documentos, manuais e 


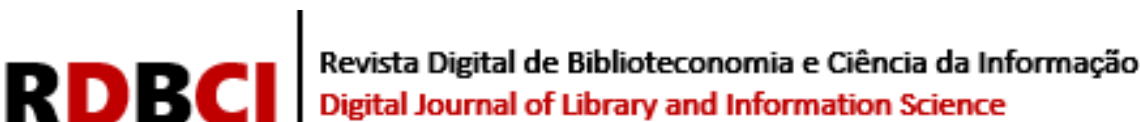

informações diretamente dos sites das editoras universitárias, da Associação Brasileira de Editoras Universitárias (ABEU) e do padrão ONIX.

Na sequência, constrói-se uma definição de metadados, baseada em autores da Ciência da Informação. Na seção três, apresenta-se uma contextualização sobre as editoras universitárias, como campo cultural, e a utilização de metadados por elas. Na seção quatro, descreve-se o padrão de metadados ONIX for Books, tal como composto por blocos e grupos de metadados e ainda outras características relevantes para o padrão. Na seção cinco, são feitas as considerações finais, seguida da apresentação das referências deste artigo.

\section{INTRODUZINDO METADADOS}

Com o avanço das TIC, muito se fala sobre metadados, entretanto falta clareza sobre o conceito uma vez que podem assumir diferentes definições para cada uma das áreas que os discutem. O objetivo deste tópico será apresentar algumas definições de metadados feitos por autores da Ciência da Informação. O intuito não é realizar uma discussão exaustiva sobre, mas oferecer uma compreensão mínima da área que possibilite uma melhor compreensão sobre metadados no contexto das editoras universitárias. Pomerantz (2015) reflete que estamos bastante condicionados aos metadados, entretanto estes se tornam "invisíveis” quando estão desempenhando seu trabalho.

Sayão (2010) destaca que o termo metadados foi utilizado principalmente em relação aos sistemas de bancos de dados, tendo por objetivo a gestão e o uso de dados, em especial, no contexto das bibliotecas e seu papel na descrição de recursos informacionais. Para o autor:

Como desdobramento, a definição minimalista e quase clássica, que enuncia que "metadados é dados sobre dados", torna-se inexpressiva e rasa diante da complexidade dos papeis atribuídos aos metadados nos diversos contextos correntes da gestão da informação; além do mais, ela não nos ajuda a entender o que é e como os metadados podem ser usados. A NISO - sigla para National Information Standard Organization - apresenta uma definição que expande o que se entende por metadados, ampliando o seu domínio de aplicação: "Metadados é a informação estruturada que descreve, explica, localiza, ou possibilita que um recurso informacional seja fácil de recuperar, usar ou gerenciar” (NISO, 2004, p.1, tradução nossa). (SAYÃO, 2010, p. 2).

Pomerantz (2015) também considera que a definição “dados sobre dados” não é muito útil do conceito "metadados" uma vez que dados são informações em potencial, brutas e não processadas antes de informarem alguém. Desenvolvendo o conceito de metadados, o autor coloca que "Ou, uma vez que uma descrição é uma declaração sobre algo, podemos definir metadados como uma declaração sobre um objeto potencialmente informativo" (POMERANTZ, 2015, p. 26, tradução nossa).

Cada dia mais crescem a geração e o uso de informações com o desenvolvimento e popularização das TIC. Então, somente um tratamento adequado para as informações registradas facilitarão seu acesso, uso, preservação e reuso, segundo Santos, Simionato e Arakaki (2014). Conforme os mesmos autores, os profissionais da Ciência da Informação e da Biblioteconomia são capazes de contribuir com metodologias e técnicas adequadas para lidar com os recursos informacionais, considerando o tratamento temático, conteúdo, e o tratamento descritivo, forma da informação. Por meio da tradição de estudos da Biblioteconomia, Pomerantz (2015) afirma que qualquer pessoa pode aplicar os princípios de descrição a qualquer coisa que precise ser descrita, especialmente depois da criação dos bancos de dados. Desta maneira, “[...] assim que a base de dados foi inventada e se tornou possível armazenar 


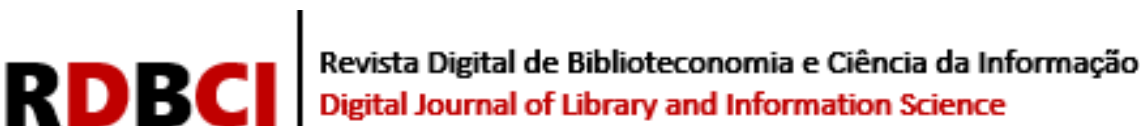

dados estruturados também se tornou possível para qualquer pessoa criar e manter os metadados eletronicamente.” (POMERANTZ, 2015, p. 14, tradução nossa).

Os sistemas de indexação e de recuperação de recursos informacionais estão cada vez mais desenvolvidos nos seus métodos, porém as informações obtidas como respostas não garantem relevância e precisão, uma vez que somente os dados de um recurso informacional não são suficientes para identificá-lo na internet (SANTOS; SIMIONATO; ARAKAKI, 2014). Segundo Santos, Simionato e Arakaki (2014), o recurso informacional é um item, um documento físico ou digital que apresenta alguma informação, que mostra um trabalho intelectual. Por exemplo, um livro, uma música, uma fotografia, seja impressa ou digital, etc. Os recursos informacionais para serem encontráveis e acessíveis devem ser descritos por metadados. Então,

Na década de 1960, Jack E. Myers, presidente e fundador da The Metadata Corporation cunhou o termo metadata (metadados) para descrever conjunto de dados que podem ser utilizados na organização, na representação e na localização de recursos e podem ser trabalhados de diferentes formas na gestão de recursos informacionais e se constituem em unidades menores do que os dados que representam (SANTOS; SIMIONATO; ARAKAKI, 2014, p. 150, destaques dos autores).

Metadados são formas simples de representar recursos, objetos informacionais complexos, ou seja, "De modo semelhante, os metadados formam/são um mapa. Os metadados são um meio pelo qual a complexidade de um objeto é representada numa forma mais simples" (POMERANTZ, 2015, p. 11, tradução nossa). Para Gilliland (2015), todos os recursos informacionais, independentemente da forma física ou intelectual, possuem três instâncias que podem ser expressas por metadados: conteúdo, intrínseco ao recurso e sobre o que ele trata; contexto, extrínseco ao recurso, ou seja, autoria, motivação, local de produção e outras informações sobre a criação e vida subsequente do objeto; estrutura, que relaciona um conjunto de associações dentro ou entre recursos, podendo ser extrínseca e/ou intrínseca.

Os autores Arakaki e Arakaki (2020) retomam uma série de autores clássicos da Ciência da Informação - Alves (2010); Alves e Santos (2013); Joudrey, Taylor e Wisser (2018); Méndez Rodríguez (2002); Pomerantz (2015); Zeng e Qin (2008, 2016) - identificaram algumas semelhanças nos conceitos de metadados, isto é, "está atribuído a uma informação estruturada para as ações de identificação, descoberta, seleção, uso, acesso e gerenciamento”. Explicam ainda que metadados podem ser produtos ou processos, isto é, ao utilizar um padrão de metadados para criar um registro informacional têm-se um produto de metadados. Os autores colocam que inicialmente os metadados foram utilizados para realizar a descrição de documentos e depois foram descobertas suas potencialidades para a pesquisa de recursos.

Segundo Gilliland (2016) ${ }^{1}$, os metadados ainda acompanham toda a vida do recurso informacional, pois além da criação é possível modificá-los e até mesmo excluí-los se houver necessidade. Logo metadados não são estáticos.

Arakaki e Arakaki (2020) retomam as tipologias de metadados, uma vez que cada tipo evidencia seu uso e função nos sistemas. Portanto, metadados administrativos são utilizados para registrar informações de origem e manutenção, para o gerenciamento e administração de coleções e recursos informacionais, para tomada de decisão; metadados de autenticação, por sua vez, tornam possível a identificação, integridade e legitimidade de um recurso; metadados de proveniência são aqueles responsáveis pela procedência do recurso, fornecendo dados sobre

1 GILLILAND, Anne. Setting the Stage. In: BACA, Murtha. (Ed) Introduction to metadata. $3^{\mathrm{a} e d . ~ L o s ~}$ Angeles: Getty Publications, 2016. Disponível em: http://www.getty.edu/publications/intrometadata/metadata-

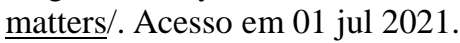




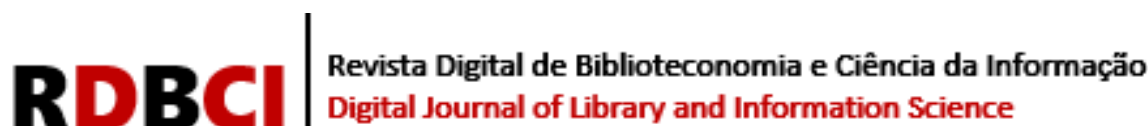

entidades, criação, modificação e relacionamentos; metadados técnicos se relacionam ao funcionamento do sistema; meta-metadados são as informações sobre o próprio registro ou sobre um conjunto de dados; metadados descritivos expõem características de identidade e contexto intelectual para descobrir, identificar, selecionar, adquirir, contextualizar e compreender um recurso informacional; metadados de direitos explicitam a propriedade e os direitos autorais; metadados de acesso e uso apresentam informações sobre como foi realizado o acesso e a utilização de um recurso; metadados estruturais relacionam-se à forma como está composto e organizado o recurso informacional; linguagens de marcação (ou markup languages) que fazem a integração de metadados e sinalizam para demais recurso estruturais ou semânticos.

Desta forma, os metadados devem ser padronizados para que garantam acesso aos dados descritivos e deem a localização de um recurso informacional na Web. Isto ainda faz com que tenham aceitação internacional e auxiliem na interoperabilidade, ou seja, no intercâmbio de metadados entre sistemas de informação. Então, isso se materializa no padrão de metadados. A adoção de um padrão faz com que centros de informação, operadores de busca da Web e lojas, por exemplo, possam trocar registros, evitando o retrabalho e apresentando mais eficiência e eficácia no processo de descrição de um recurso informacional, segundo Santos, Simionato e Arakaki (2014). Sendo assim,

\begin{abstract}
Na implementação de metadados, deve ser realizada uma análise de domínio, ou seja, devem ser criadas estruturas que garantam a utilização de padrões de descrição e que favoreçam a interpretação de cada metadado. Sendo que esses metadados atuarão como possíveis pontos de acesso tanto ao recurso isoladamente, quanto aos seus relacionamentos com outros recursos informacionais (SANTOS; SIMIONATO; ARAKAKI, 2014, p. 151).
\end{abstract}

Segundo Pomerantz (2015), a existência de metadados pressupõe a existência de dados estruturados e organizados em conformidade com um modelo de dados, isto é, uma representação de tipos de entidades descritas, com suas propriedades e o relacionamento entre essas instâncias. Então:

A existência de metadados é parcialmente baseada na existência de dados
estruturados. Os dados estruturados são organizados de acordo com um modelo de
dados, que é uma representação dos tipos de entidades descritas pelos dados, as
propriedades dessas entidades e as relações entre elas (POMERANTZ, 2015, p. 140,
tradução nossa).

Zeng e Qin (2016) definem padrão de metadados como documentos formais que estabelecem critérios uniformes, métodos, processos e práticas, tendo objetivos específicos que guiam o design, a criação e a implementação de estruturas de dados, valoração, conteúdo e troca eficiente e consistente. Os autores colocam que os padrões de metadados devem respeitar os seguintes princípios: modularidade, extensibilidade, refinamento e multilinguismo. Sendo assim, "Esses princípios também têm um efeito direto sobre como implementar projetos de metadados e, simultaneamente, torná-los sustentáveis para utilização e preservação de longo prazo, bem como interoperáveis para compartilhamento e reuso” (ZENG; QIN, 2016, p. 28, tradução nossa).

Ramalho (2019) argumenta que a interoperabilidade é central para que livros e capítulos se tornem visíveis, além da acessibilidade na recuperação de textos completos on-line. Os metadados devem ser comunicados de forma correta, por isso, existem padrões adotados mundialmente pelos domínios que possibilitarão a comunicação entre sistemas, segundo a autora. 


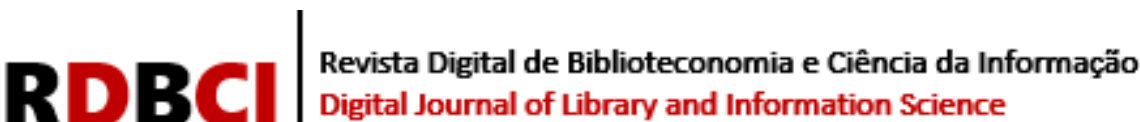

Na prática, as linguagens ajudam a enviar grandes fluxos de dados de livros para lojas e bases de dados de forma padronizada e facilmente interpretável por máquinas, sem a necessidade de preenchimento de planilhas com dados copiados e colados, ou estabelecem normas para a coleta automatizada de dados, facilitando o uso por bibliotecas, por exemplo (RAMALHO, 2019, p.95).

Segundo Zeng e Qin (2016), a criação de metadados envolve ação humana e ferramentas de software, pois a combinação de ambas cumpre os requisitos funcionais de criação de metadados descritivos, gerenciamento de direitos, descoberta de recursos/metadados administrativos e a preservação. Desta maneira, diferentes padrões de metadados foram criados para atender populações específicas porque a prática comprovou que apenas um padrão de metadados não compreende todas as particularidades de descrição e gerenciamento que todos os recursos informacionais exigem.

Segundo Zeng e Qin (2016), os padrões de metadados da indústria editorial estão relacionados aos metadados de direitos. Considerando o mercado editorial e livreiro, a criação e adoção de metadados se justifica da seguinte maneira: "Com o rápido crescimento da publicação eletrônica, a indústria de publicação e outros participantes, incluindo as 'autoeditoras' (self-publishers), começaram a implementar e a compartilhar de forma eficiente esses dados com parceiros comerciais e clientes.” (ZENG; QIN; 2016, p. 463, tradução nossa).

Um reconhecido e importante padrão de metadados para o setor editorial e livreiro é o ONIX for Books (ONline Information eXchange). Na seção 4, o padrão de metadados é descrito detalhadamente.

\section{AS EDITORAS UNIVERSITÁRIAS E OS METADADOS}

As editoras universitárias são consideradas lugares privilegiados de difusão do conhecimento científico produzido dentro da universidade seja para o público interno ou externo. Bufrem e Garcia (2014) consideram que as editoras universitárias exercem um papel importante no desenvolvimento científico e, amplamente, no desenvolvimento do país. Isto evidencia a variedade de temas publicados de forma a atender ao público, segundo as autoras. Então, as editoras universitárias constituem um campo cultural próprio. Assim:

A editoração universitária tem reconhecidamente funções específicas na medida em que se distingue por temas, técnicas e estudos dotados de valor no seu campo de atuação. Suas “marcas de distinção” - especialidades, maneiras e estilos - são aceitas como culturalmente pertinentes e, portanto, suscetíveis de serem percebidas e assim reconhecidas [...] (BUFREM, 2015, p. 222).

Tendo como foco as pesquisas realizadas nas universidades, as editoras universitárias delimitam os temas sobre os quais publicam; em geral, essas publicações são livros. Estes se consolidaram ao longo do tempo como um instrumento portador do conhecimento. Com o desenvolvimento das TIC, o livro ganha novos suportes, por exemplo, o livro digital ou e-book. Andrade e Araújo (2017) concluem que o mercado editorial deve também modificar-se a fim de atender ao consumidor digital, não apenas na construção de um website com catálogo ou loja virtual, mas também nas suas políticas editoriais. Desta forma:

A inserção das editoras universitárias no mercado editorial digital não depende exclusivamente da disponibilização de páginas na Web, mas de toda uma mudança em suas políticas editoriais. Dois movimentos tende a auxiliar essa inserção: o movimento de acesso aberto e a utilização de plataformas para a publicação e 


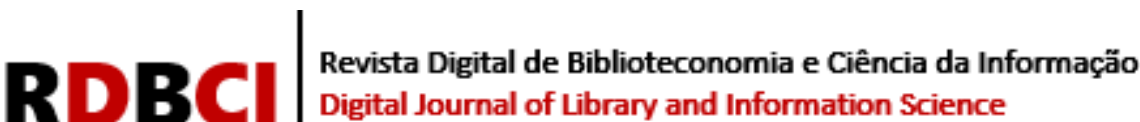

gerenciamento dos livros digitais (ANDRADE; ARAUJO, 2017, p. 1).

Para Baca (2016), digitalizar não garante acessibilidade nem que os recursos informacionais serão encontrados, localizados, compreendidos ou utilizados pelos crescentes usuários on-line. Entretanto, a digitalização aliada aos metadados elaborados cuidadosamente podem melhorar o acesso do usuário final. Tendo em vista que os equipamentos eletrônicos e os softwares se tornam ultrapassados rapidamente, padrões de metadados independentes de sistemas podem ser reutilizados, migrados e disseminados de diversas formas, que não são previsíveis neste momento, segundo Baca (2015).

Gilliland (2016) salienta que, no ambiente on-line de acesso imediato, os metadados podem garantir a autenticidade e a completude, documentam o contexto e conteúdo, fornecem uma série de pontos de acesso para os diversos usuários e apresentam algumas informações tratadas por profissionais da informação quanto ao recurso informacional. Desta forma,

Em todas essas interpretações diversas, os metadados não apenas identificam e descrevem um objeto de informação; também documentam como esse objeto se comporta, sua função e uso, sua relação com outros objetos de informação e como deve ser e tem sido gerenciado ao longo do tempo (GILLILAND, 2016, on-line, tradução nossa).

Percebe-se também uma preocupação e necessidade da adoção de sistemas de metadados pelas editoras universitárias. O tema vem sendo discutido pela ABEU nos últimos anos, objetivando oferecer formação, diretrizes e ajuda para que as editoras consigam se atualizar. Alguns exemplos são Ramalho² (2019), Ramalho e Gutierre (2020) e Fachin (2020).

A realidade das editoras universitárias públicas, especialmente, é bastante diversa considerando o número de publicações anuais, equipes de trabalho, recursos financeiros e modelos de negócio adotados. Por exemplo, algumas editoras publicam apenas livros digitais em acesso aberto (Editora UEMG e EDUFRO) e outras comercializam livros impressos e possuem alguns títulos ou selos de $e$-books em acesso aberto (Fundação Editora da UNESP e Editora UNICAMP).

Ramalho (2019) considera que a tecnologia sempre influenciou o livro tanto no fazer como na leitura e apresenta dois marcos tecnológicos: a invenção de Gutenberg que possibilita que manuscritos sejam impressos e os livros em formato digital, que coexistem com os impressos atualmente. A autora reconhece que livros impressos e digitais se complementam, agregando funcionalidades e recursos.

Conforme Pomerantz (2015), o setor editorial possui uma história em curso com metadados que, atualmente, ainda se encontra em desenvolvimento. Originalmente, os metadados de uma publicação eram simples e descritivos, tais como, editora, data de publicação, ISBN etc. Com o surgimento dos e-books e das plataformas de autopublicação (como Kindle Direct, Lulu), as editoras têm percebido que a riqueza e qualidade dos metadados são determinantes para a descoberta de um recurso informacional (POMERANTZ, 2015).

Sobre metadados, Ramalho (2019, p. 89) os vê da seguinte maneira:

A função principal é identificar e descrever um determinado conteúdo, que, no caso de livros, refere-se a todas as informações bibliográficas que descrevem e identificam a obra como um todo. Os metadados possuem usos e funções definidos conforme as necessidades particulares de classificação, organização e recuperação da informação.

2 Amanda Ramalho é uma das coordenadoras do programa SciELO e diretamente responsável pela SciELO Livros. 


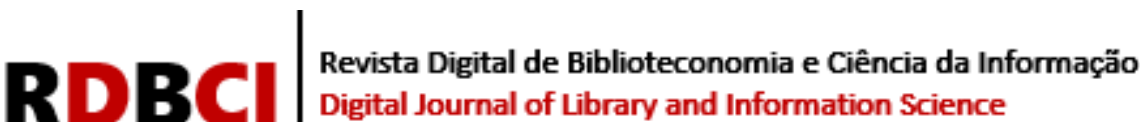

Segundo Ramalho (2019), os livros acadêmicos e científicos necessitam utilizar bases de dados com segurança e reconhecimento para que cumpram sua função de disseminação do conhecimento, considerando ainda a conservação e preservação de documentos em um momento de democratização do conhecimento. Principalmente, trabalhando com livros em acesso aberto, Ramalho (2019) considera que disponibilizá-los não é o suficiente, pois:

É necessário, além de adotar formatos que possibilitem a preservação, incluir o livro
nos principais canais de pesquisa utilizado pelos usuários, de modo a ampliar as
possibilidades de localização e descoberta do livro e seus capítulos. Desse modo,
destaca-se a importância dos metadados e a interoperabilidade, que promovem a
visibilidade e a recuperação dos textos completos on-line (RAMALHO, 2019, p. 98).

Ao expor o questionamento "Metadados: por que se preocupar com isso?”, Ramalho e Gutierre (2020) enumeram os seguintes benefícios para as editoras universitárias: organização do fluxo editorial, desde o recebimento do manuscrito até a venda do livro publicado; possibilidade de realização de levantamentos rápidos de informações para a tomada de decisões; integridade dos dados; compartilhamento de dados com os serviços do mercado; e facilidade na recuperação do livro. Os autores afirmam que as editoras, quando utilizam um sistema de metadados, têm economia em seus gastos operacionais e de trabalho, além da ampliação da venda de livros físicos, pois os títulos publicados são recuperados com maior facilidade pelos leitores potenciais, o que resulta no aumento de vendas.

Register e McIlroy (2012 apud Zeng e Qin, 2016) apresentam as principais atividades que acompanham um suporte de metadados editoriais e livreiros: criação e aquisição de conteúdo, registro do ISBN, editorial, produção, marketing de pré-publicação, distribuição nos canais de venda, pré-publicação das transações de venda, publicação em si, marketing póspublicação, pesquisa e descoberta pelo usuário, além da seleção, transações de venda póspublicação, rastreamento de vendas e inteligência de negócios.

Fachin (2020) argumenta que os metadados bem definidos e informados devidamente, em especial, no correto preenchimento dos sistemas próprios ou em parcerias, é uma obrigação e responsabilidade das editoras universitárias em virtude do impacto na encontrabilidade do livro pelo usuário-cliente. Segundo Fachin (2020), a atualização das equipes editoriais e ainda ações unificadas e conjuntas, são fundamentais para que as editoras atendam estes novos requisitos informacionais, então:

Deste modo, entendo ser de super, mega e urgentíssima importância que as editoras e suas equipes se atualizem, estudem, busquem por esclarecimentos, por explicações de como funcionam as planilhas, os dados solicitados na alimentação de bancos ou bases de dados, sejam para catálogos, sejam em distribuidores, sejam para feiras, sejam para associações parceiras e/ou seja em seu próprio sistema automatizado utilizado. É necessário entender cada campo e o preencher adequadamente, só assim a recuperação, a interoperação, a junção destes dados permitirão a unificação em ações conjuntas e na divulgação aos clientes - é garantir a venda de seus títulos, numa disputa de mercado (FACHIN, 2020, online).

A confiabilidade e padronização dos dados também é destacada por Fachin (2020), por impactar na divulgação, recuperação e comercialização em feiras virtuais, por exemplo. Eventos, estes, vistos pela autora como uma saída para venda de livros e pela sustentabilidade das editoras universitárias mesmo que os dados sejam utilizados para o preenchimento de planilhas. A autora inclusive reflete sobre o impacto da pandemia sobre as editoras universitárias:

Tempos de pandemia! Internet como ponto de contato e de vida em tempos atuais e, 


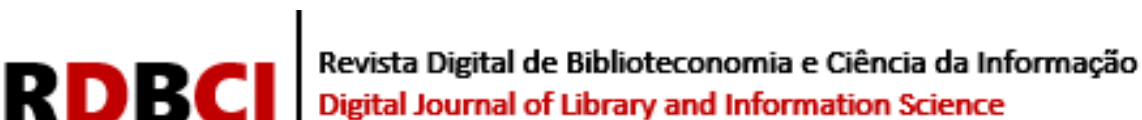

sem o devido cadastramento de metadados corretos, nossa divulgação e arrecadação tornam-se ineficazes e a cada dia nos tornamos invisíveis neste mercado concorrido da virtualidade (FACHIN, 2020, online).

Especificamente refletindo sobre a descoberta de recursos, encontrabilidade ou recuperação da informação, Pomerantz (2015) esclarece o que se entende por tais termos: “A descoberta de recursos é, como você pode esperar, o processo de identificação de recursos de informação que podem ser relevantes para minha necessidade de informação” e acrescenta: “A descoberta de recursos depende de bons metadados como estes” (POMERANTZ, 2015, p.1516, tradução nossa).

Gilliland (2016) faz a ressalva de que a criação e manutenção continuada de metadados são atividades complexas, demoradas e exigem recursos intensivos, portanto só se justificam quando existe uma diretriz institucional, e ainda outros incentivos de gestão de riscos ou sabese antecipadamente que os metadados poderão ser reutilizados e explorados de diversas maneiras. A adoção, criação e manutenção de metadados pelas editoras universitárias brasileiras podem ser associadas a esta última justificativa apresentada pela autora.

Por este motivo, Baca (2016) ressalta que as regras e processos que envolvem metadados devem ser aplicados institucionalmente para evitar lacunas, falhas e mesmo retrabalho das unidades de uma instituição. A autora ainda acrescenta que as instituições devem escolher com cuidado os padrões de metadados e vocabulários controlados para melhor descrever e fornecer acesso à suas coleções e recursos informacionais.

Desta forma, buscou-se, neste item, elaborar uma breve descrição da função social e da importância das editoras universitárias, atendo-se ao contexto brasileiro. Ainda foram expostos os benefícios da adoção de um sistema de metadados pelas editoras universitárias brasileiras a partir de discussões feitas por profissionais e pesquisadores da área. Em seguida, explana-se sobre o padrão de metadados ONIX.

\section{O PADRÃO DE METADADOS ONIX FOR BOOKS}

Segundo Ramalho (2019), no Brasil, não se identificou nenhuma base de dados nacional que regulamente a criação e circulação de registros de metadados automatizados e interoperáveis para livros, ainda que existam instituições que regulamentem registros de publicações nacionais, como a Agência Brasileira do ISBN (International Standard Book Number / Padrão Internacional de Numeração de Livro) e a Câmara Brasileira do Livro. Ramalho (2019) destaca que a ABNT NBR ISSO 2108:2006 define que os metadados para o ISBN sejam compatíveis com o padrão ONIX Internacional, porém não são oferecidas mais instruções sobre formas e possibilidades de coleta e reuso de registros, além da falta de normatização para o número de campos a serem cadastrados minimamente de um livro.

O ONIX for Books é ainda um dos formatos de metadados adotados pela SciELO Livros (Scientific Electronic Library Online) que a partir deste formato consegue interoperar com outras bases de dados (por exemplo, DOAB- Directory of Open Access Books), livrarias e lojas virtuais (Kobo, Amazon, Google Play) e serviços (Google Acadêmico e WorldCat), fazendo com que seus registros sejam facilmente encontráveis e recuperáveis. Tais informações evidenciam a relevância desse padrão de metadados no contexto nacional e internacional para as editoras e mercado livreiro. Por isso, escolheu-se o ONIX for Books neste trabalho.

O ONIX for Books Product Information Format é reconhecido internacionalmente como um padrão de metadados bibliográficos de livros tanto impressos quanto digitais para a devida representação e compartilhamento na Web. A primeira versão foi publicada no ano 2000 


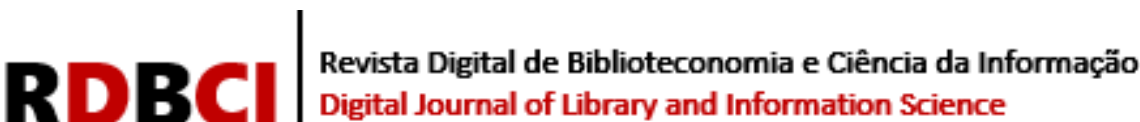

e, estando, atualmente na versão 3.0, de 2009 cuja última atualização (3.0.7) foi realizada em 2019 pela EDItEUR, empresa responsável pelo padrão. Reconhecidamente, é um padrão de metadados rico que proporciona aos editores o gerenciamento e compartilhamento de informações e dados altamente estruturados e padronizados com distribuidores e/ou lojas do varejo de forma automática e com ausência de ambiguidades. O ONIX for Books utiliza a linguagem XML (eXtensible Markup Language), com o formato DTD (Document Type Definition) e o esquema XSD (XML Schema Definition).(ALVES, 2018); (SERRA, 2019); (RAMALHO, 2019); (RAMALHO E GUTIERRE, 2020); (EDItEUR, 2020).

Esclarecendo sobre o XML, Zeng e Qin (2016) afirmam que é um formato universal de documentos e dados na Web. Fornecendo uma sintaxe formal que descreve as relações entre entidades, elementos e atributos que compõem um documento XML, além de permitir que os computadores façam o reconhecimento das partes componentes destes documentos. Para as autoras:

\footnotetext{
As especificações XLM alcançaram seus objetivos pretendidos: usabilidade da Internet, usabilidade de propósito geral, compatibilidade SGML, estrutura que facilita o desenvolvimento de software de processamento, minimização de recursos opcionais, legibilidade, formalidade, concisão e facilidade de autoria. (ZENG; QIN, 2016, p. 130, tradução nossa)
}

Segundo EDItEUR (2020), o padrão ONIX é um formato de dados comerciais, criado para ser utilizado globalmente, portanto não adota uma língua única ou características específicas de publicações nacionais. A EDItEUR (2020) elenca dois benefícios principais na utilização do ONIX por editoras: em primeiro lugar, como um formato de comunicação, fornece informações valiosas sobre uma cadeia de produtos, padronizadas e consistentes, direcionadas para distribuidores, atacadistas, varejistas, agregadores de dados e empresas maiores, reduzindo custos, pois não precisam utilizar vários formatos; em segundo lugar, ao fornecer um padrão, ONIX impulsionou uma melhora nos sistemas de informação internos, reunindo metadados necessários para descrição e promoção do catálogo de títulos. Para os parceiros ou sistemas internos das editoras, a utilização do ONIX ainda proporciona um carregamento mais eficiente e rápido de atualizações do produto, com necessidade reduzida de ajustes manuais e, consequentemente, com menor risco de erros, conforme informa a EDItEUR (2020). É importante ressaltar que o ONIX for Books não é um banco de dados nem um design para, mas é uma forma de comunicar com bancos de dados, ainda que vários membros da EDItEUR e outras organizações tenham desenvolvido softwares baseados no padrão ONIX ou encontrado outras soluções que o implementem.

Zeng e Qin (2016) definem o ONIX da seguinte forma:

\begin{abstract}
ONIX é uma família de formatos XML para comunicar metadados ricos sobre livros, seriados e outros mídias publicadas utilizando elementos de dados comuns, “compostos” e listas de códigos. O padrão ONIX define uma lista de campos de dados sobre a publicação e descreve como enviar esses dados numa "mensagem de ONIX" (ZENG; QIN; 2016, p. 464, tradução nossa).
\end{abstract}

A utilização se inicia com "a message", ou seja, uma mensagem do ONIX for Books que apresenta um cabeçalho, identificando o remetente acompanhado de um carimbo com a data e, opcionalmente, pode apresentar um destinatário. O corpo da mensagem é composto por um número ilimitado de registros de produtos, cada um em relação a um único produto, em geral, comercializável; mas ainda pode registrar um recurso que é vendido como parte de um conjunto ou um conjunto com partes vendidas separadamente, de acordo com EDItEUR (2009). Veja o esquema no Quadro 1. 


\section{Devista Digital de Biblioteconomia e Ciência da Informação \\ Digital Journal of Library and Information Science}

Quadro 1: "A message" ou novo registro no ONIX for Books

\begin{tabular}{|c|c|}
\hline$<$ ?xml version="1.0"?>> & \\
\hline$<$ ONIXMessage release=" 3.0 " $>$ & \\
\hline$<$ Header $>\ldots \ldots \ldots . .</$ Header $>$ & Message header \\
\hline$<$ Product $1>\ldots \ldots .</$ Product $>$ & Product 1 record \\
\hline$<$ Product $2>\ldots \ldots .</$ Product $>$ & Product 2 record \\
\hline$<$ Product $n>\ldots \ldots .<$ Product $>$ & Product $n$ record \\
\hline$<$ OONIXMessage $>\quad$ Fonte: EDItEUR $(2009$, P. 9). \\
\hline
\end{tabular}

Segundo Pomerantz (2015), metadados não podem existir sem um container, isto é, os metadados devem estar registrados em algum formato seja físico ou digital, então, "Do mesmo modo, um registro de metadados é ele mesmo um recipiente para os dados sobre um" (POMERANTZ, 2015, p. 22, tradução nossa). Sendo assim, o registro em ONIX do produto começa com alguns elementos de metadados de registro (ou de manutenção), segundo EDItEUR (2009), nos quais são obrigatórios um identificador e uma notificação codificada, por exemplo, o ISBN. Outros identificadores secundários podem ser enviados. O restante do registro é subdivido em sete grupos. EDItEUR (2009) destaca duas questões: a primeira delas diz respeito ao bloco 6, que contêm informações repetidas dos demais grupos, e ainda pode ser repetido inteiramente a cada novo destinatário para o qual os registros forem enviados; a segunda delas é que, como visto na tabela abaixo, o grupo 7 está fora da ordem, pois deve ser considerado em conjunto com o grupo 2. Observe o esquema:

Quadro 2: Estrutura de um registro de produto em ONIX for Books

\begin{tabular}{|c|c|c|c|}
\hline \multicolumn{3}{|l|}{$<$ Product> } & \\
\hline \multicolumn{3}{|l|}{ Record Metadata } & Group P.1 \\
\hline \multicolumn{3}{|l|}{ Product numbers } & Group P.2 \\
\hline$<$ DescriptiveDetail> & $\ldots \ldots$ & $</$ DescriptiveDetail $>$ & Block 1 \\
\hline <Collatera|Detail> & & $</$ CollateralDetail $>$ & Block 2 \\
\hline$<$ PromotionDetail> & & $</$ PromotionDetail $>$ & Block 7 \\
\hline$<$ ContentDetail $>$ & $\ldots \ldots \ldots \ldots$ & $</$ ContentDetail $>$ & Block 3 \\
\hline <PublishingDetail> & & $<\mid$ PublishingDetail> & Block 4 \\
\hline$<$ RelatedMaterial> & & $<\mid$ RelatedMaterial $>$ & Block 5 \\
\hline$<$ ProductSupply> & & $<$ ProductSupply $>$ & Block 6 \\
\hline$<$ PProduct $>$ & & & \\
\hline
\end{tabular}

Fonte: EDItEUR (2009, p. 9).

Segundo EDItEUR (2009), cada um dos blocos descritos no quadro 2 é composto por um ou mais grupos numerados. Cada um desses grupos de dados é definido a partir da reunião de elementos relacionados pela sua função e que, na apresentação detalhada do registro, serão apresentados em conjunto. Os grupos consistem em uma combinação de elementos únicos em XML ou em um agrupamento de dados (chamados na versão original de "composites”) que expressam a estrutura semântica dos metadados. Tanto os dados únicos quanto os agrupamentos 


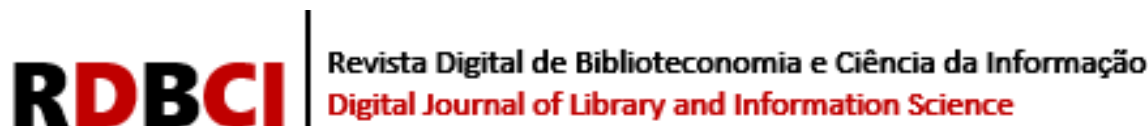

podem ter caráter obrigatório ou opcional e ser necessária sua repetição. EDItEUR (2009, p. 10, tradução nossa) destaca que "A ordem em que os elementos e compostos ocorrem dentro do grupo é crítica (e isso se aplica igualmente à ordem dos grupos dentro de um bloco e à ordem dos blocos dentro de um registro de produto)", isto é, a ordem dos elementos e compósitos é extremamente importante para os registros em ONIX.

Em seguida, construiu-se um quadro com os blocos, títulos e breves descrições com o objetivo de oferecer uma visão panorâmica do padrão. Dentro de cada bloco existe uma sequência de grupos correspondentes de maneia pontual para cada informação que deve ser preenchida; entretanto não serão detalhados neste artigo, mas que estão disponíveis em EDItEUR (2009).

Quadro 3. Descrição dos Blocos que compõe o ONIX for Books.

\begin{tabular}{|c|c|c|}
\hline BLOCO & TITULO & DESCRIÇÃO \\
\hline 1 & $\begin{array}{l}\text { Descriptive Detail } \\
\text { (Detalhes Descritivos) }\end{array}$ & $\begin{array}{l}\text { Engloba os grupos de P. } 3 \text { a P.13. Apresenta informações detalhadas } \\
\text { sobre forma e o conteúdo do recurso, tais como: forma do produto } \\
\text { (dimensões físicas ou formatos do arquivo, por exemplo); partes do } \\
\text { produto; coleção; título do produto; autoria; detalhes do evento } \\
\text { (para obras resultadas de conferências ou eventos artísticos, } \\
\text { esportivos etc); edição (tipo da edição, número da edição e } \\
\text { declaração da edição); língua (se for uma tradução, pode apresentar } \\
\text { a original e a traduzida); extensões, ilustrações e conteúdo auxiliar; } \\
\text { assunto sem restrição de quantidade, utilizando cabeçalhos de } \\
\text { assuntos e códigos de classificação de assunto (Thema, BISAC, CLIL, } \\
\text { Dewey, Library of Congress) e/ou listas livres de palavras-chave; } \\
\text { público-alvo. }\end{array}$ \\
\hline 2 & $\begin{array}{l}\text { Collateral Detail } \\
\text { (Detalhes Concomitantes) }\end{array}$ & $\begin{array}{l}\text { Engloba os grupos P.14 a P.17. Apresenta as informações com um } \\
\text { pequeno índice textual (text content) em HTML, resumindo todo o } \\
\text { registro; índice de citações (cited content); recursos de suporte, } \\
\text { feitos para ligar diferentes recursos, como imagens, clipes de áudio, } \\
\text { outros textos, vídeos, jogos etc; e premiações com detalhes. }\end{array}$ \\
\hline 7 & $\begin{array}{c}\text { Promotion Detail } \\
\text { (Detalhes de Promoção) }\end{array}$ & $\begin{array}{l}\text { Formado por um único dado (grupo P.27) que apresenta } \\
\text { informações sobre a promoção e divulgação do livro, por exemplo, } \\
\text { palestras e viagens do autor. }\end{array}$ \\
\hline 3 & $\begin{array}{l}\text { Content Detail } \\
\text { (Detalhes de Conteúdo) }\end{array}$ & $\begin{array}{l}\text { Formado por um único dado (grupo P.18) que estrutura índices } \\
\text { detalhados para livros. }\end{array}$ \\
\hline 4 & $\begin{array}{l}\text { Publishing Detail(Detalhes } \\
\text { de Publicação) }\end{array}$ & $\begin{array}{l}\text { Engloba os grupos (P.19 a P.21). Apresenta as informações de } \\
\text { impressão e editora; status global de publicação e copyright; direito } \\
\text { de venda e restrições. }\end{array}$ \\
\hline 5 & $\begin{array}{c}\text { Related Material } \\
\text { (Materiais Relacionados) }\end{array}$ & $\begin{array}{l}\text { Engloba os grupos (P.22 e P.23). Apresenta as informações de } \\
\text { trabalhos e produtos relacionados. }\end{array}$ \\
\hline 6 & $\begin{array}{l}\text { Product Supply } \\
\text { (Fornecimento de } \\
\text { Produtos) }\end{array}$ & $\begin{array}{l}\text { Engloba os grupos (P.24 a P.26). Apresenta as informações de } \\
\text { mercado (demarcando o território e especificando restrições nas } \\
\text { vendas); status e data de publicação no mercado; detalhamento das } \\
\text { fontes de distribuição, disponibilidade, preços etc. dentro do } \\
\text { mercado. }\end{array}$ \\
\hline
\end{tabular}

Fonte: elaboração própria (2021) 


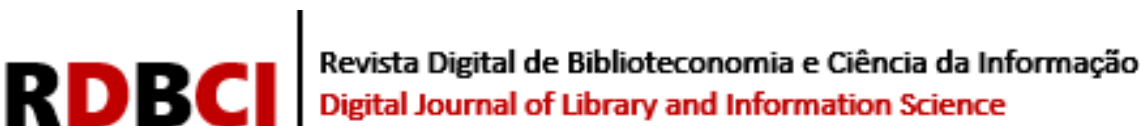

Pomerantz (2015) explica que um registro de metadados é um conjunto de declarações de sujeito-objeto-predicado sobre um único recurso. Além do mais, um registro em metadados é um "representante" do recurso informacional em si, portanto deve ser bastante simples e curto: "Uma das funções de um registro de metadados é ser um proxy (representação, substituição) para um objeto e, para um proxy ser eficaz, geralmente deve ser mais simples do que o objeto original.” (POMERANTZ, 2015, p. 92, tradução nossa). Sobre isto, a EDItEUR (2009) afirma que o ONIX for Books pode parecer para algumas pessoas muito complexo e grande, mas isto se faz necessário devido à complexidade do objeto descrito e das demandas dos diferentes mercados editoriais.

O registro de um produto em ONIX deve ter pelo menos os blocos 1 , 4 e 6 , responsáveis pela descrição do produto, identificação do editor, detalhamento sobre o fornecimento para os mercados, conforme EDItEUR (2009). Na prática, EDItEUR (2009) afirma que é bastante incomum encontrar registros completos sem os blocos 2 e 5 . O bloco 3 é menos comum, porém permite metadados ricos para capítulos o que pode aprimorar o registro do livro todo. O bloco 7 foi introduzido na última versão para descrever eventos de divulgação e promoção do livro, como, sessões de autógrafos do autor.

Segundo Pomerantz (2012), a qualidade dos dados é algo muito importante inclusive a descrição dos metadados está diretamente relacionada com a descoberta de um recurso informacional pelo usuário. Assim, um registro incompleto ou com erro ortográfico pode impedir que um usuário encontre um recurso informacional relevante para sua pesquisa. Por isso, a EDItEUR (2009) ressalta a importância das "codelists", ou seja, uma série de vocabulários controlados, utilizados em conjunto com elementos de dados em XML e atualizadas duas vezes ao ano, geralmente.

Alves (2018) apresenta que a adoção do ONIX traz agilidade do processamento dos dados entre editora e seus parceiros, pois todos utilizam a mesma estrutura de dados. Para a editora que quiser adotar o ONIX for Books, existem algumas opções listadas pela EDItEUR (2009): confecção de um software próprio, comprar um sistema pronto para gestão de dados ou contratar um serviço on-line que receba os dados e os entregue em ONIX. Para as editoras universitárias que já possuem parceria com a SciELO Livros, cada livro disponibilizado pela base recebe a descrição em ONIX for Books. Alves (2018), Ramalho (2020) e Fachin (2020) apresentam mais dois serviços de descrição e distribuição de metadados editoriais e livreiros no padrão ONIX, são eles: MercadoEditorial.org e Metabooks.

Ainda que na descrição do padrão ONIX tenha sido enfatizada sua possibilidade de integração com a venda de livros por grandes livrarias e lojas, o benefício da adoção de metadados também vale para os livros em acesso aberto, fazendo com que sejam encontrados e recuperados integralmente com mais facilidade para o usuário-cliente.

É importante também ressaltar que existem estudos que apresentam propostas de interoperabilidade entre os padrões de metadados editoriais e livreiros, ONIX for Books e o padrão MARC 21 (Machine-Readable Catalog) do domínio bibliográfico, utilizado em bibliotecas (ALVES, 2018). Ainda que cada padrão tenha sido criado para as necessidades de cada domínio, é possível encontrar semelhanças, pois expressam olhares diferentes para o mesmo objeto. Esses domínios podem intercambiar dados sobre publicações com objetivos comerciais: de identificação e descoberta na rede, além da comparação de preços para seleção e aquisição por parte de bibliotecas e, inclusive, dos usuários. Também auxilia na disseminação do conhecimento, ao agilizar a atribuição de identificadores, padronizar assuntos e atualizar dados, aprimorando os catálogos das bibliotecas. Este torna a catalogação do recurso, facilitando os serviços e evitando o retrabalho e, ainda, possibilitando o acesso, a identificação e a obtenção do recurso físico ou digital. 


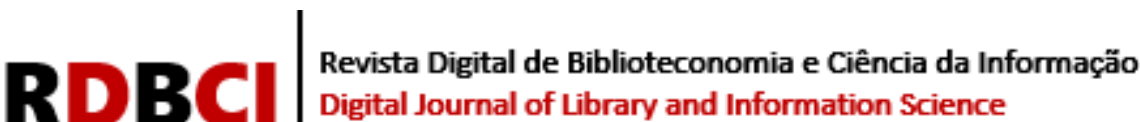

No âmbito das bibliotecas, a interoperabilidade entre os padrões pode aprimorar os registros bibliográficos, trazendo informações diretamente da fonte, fornecendo uma resposta melhor para o usuário, então, “Com informações adicionais no catálogo, como onde comprar e qual o preço do livro, por exemplo, é possível que o usuário navegue no catálogo e além dele ampliando seu acesso ao recurso informacional” (ALVES, 2018, p. 249).

Serra (2019) expõe uma proposta de modelos de dados construídos a partir do escopo da Web Semântica que interopera metadados em ONIX for Books, Schema Book e MARC 21, fornecidos por editoras e aproveitados nas bibliotecas automaticamente, auxiliando em uma gestão mais eficiente e eficaz para $e$-books na unidade de informação. "Os fornecedores para bibliotecas são os editores, os distribuidores e os agregadores de conteúdo” (SERRA, 2019, p. 36). Detendo-se aos livros digitais, a autora explica que as bibliotecas têm dificuldade em gerenciar a contratação e licenciamento destes recursos, pois as plataformas utilizadas pelos fornecedores para leitura não são apresentadas em padrão MARC 21. Essa baixa qualidade dos metadados torna dificultosa e não satisfatória a descoberta de e-books no catálogo da biblioteca, além de tornar a catalogação custosa, pois os dados precisam ser ajustados.

Percebe-se que a aproximação desses dois domínios, editorial e bibliográfico, pode apresentar novas possibilidades informacionais e impacto positivo nas pesquisas e práticas das editoras e bibliotecas. Isto se torna especialmente relevante no contexto da editoração universitária, porque toda universidade tem um sistema de bibliotecas.

\section{CONSIDERAÇÕES FINAIS}

As editoras universitárias têm um papel importante dentro da universidade, pois funcionam como apoio para o ensino, a pesquisa e a extensão, além de serem canais de divulgação e disseminação científica. As editoras universitárias constituem um contexto amplo de atuação, já que seu objetivo final não é o lucro, tal como nas editoras comerciais tradicionais. Mesmo assim, para que as editoras universitárias ampliem sua presença no campo da divulgação científica, devem estar atentas às novas necessidades impostas pelo desenvolvimento das TIC, as formas de recuperação da informação pelos mecanismos de busca e integração com lojas virtuais ou bases de dados seja para possibilitar a venda de seus livros ou o acesso aos e-books gratuitos.

Desta forma, este artigo contextualizou as editoras universitárias e argumentou sobre os vários benefícios de adoção de um padrão de metadados para registro informacional de seus livros e outras publicações; introduziu o conceito de metadados, a partir do escopo da Ciência da Informação; e construiu uma exposição sobre o padrão de metadados ONIX for Books, amplamente adotado pelo mercado editorial mundial, mecanismos de busca na Web e inúmeros serviços de disponibilização e divulgação da informação.

Conclui-se, então, que as editoras universitárias brasileiras precisam refletir suas estratégias e modelos de negócios na era das TIC. Implantar um sistema de metadados aumenta as possibilidades de atuação, de maneira que os livros podem ser encontrados com mais facilidade seja para a compra ou download, poupando o tempo do usuário. O ONIX for Books é um padrão de metadados especialmente desenvolvido para a indústria editorial e livreira, amplamente utilizado pelo mundo, tem sua eficiência comprovada, atende à complexidade descritiva de livros e fornece metadados ricos e padronizados. As editoras universitárias, muitas vezes, não possuem rendimentos ou recursos financeiros abundantes, por isso soluções gratuitas ou parcerias com bases de dados nacionais ou bibliotecas universitárias podem ser exploradas.

RDBCl: Rev. Dig. Bibliotec e Ci. Info. / RDBCl: Dig. J. of Lib. and Info. Sci. | Campinas, SP | v.19| e021032 | 2021 


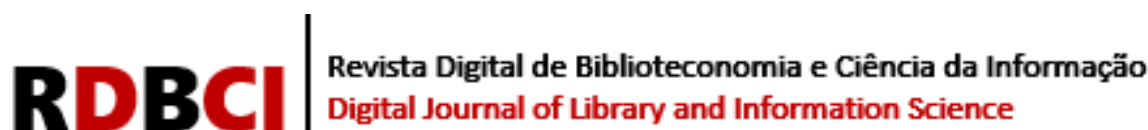

\begin{tabular}{l} 
CRediT \\
RECONHECIMENTOS: Não é aplicável. \\
FINANCIAMENTO: Este estudo foi financiado pelo Programa de Demanda Social da Coordenação de \\
Aperfeiçoamento de Pessoal de Nível Superior- Brasil (CAPES), processo N.88887.615482/2021-00. \\
CONFLITOS DE INTERESSE: Os autores certificam que não têm interesse comercial ou associativo que represente \\
um conflito de interesses em relação ao manuscrito. \\
APROVAÇÃO ÉTICA: Não é aplicável. \\
DISPONIBILIDADE DE DADOS E MATERIAL: https://zenodo.org/record/5643847 \\
https://doi.org/10.5281/zenodo.5643846. \\
CONTRIBUIÇÕES DOS AUTORES: Conceitualização, Administração do Projeto, Escrita - revisão \& edição: MAIA, C.; \\
FARIAS, G; FARIAS, M.; Curadoria de dados, Análise formal, Investigação, Metodologia, Escrita - Rascunho original: \\
MAIA, C.; Recursos, Supervisão, Visualização: FARIAS, G.; FARIAS, M.; Aquisição de Financiamento: não é aplicável. \\
\hline
\end{tabular}

\section{REFERÊNCIAS}

ANDRADE, Roberia de Lourdes de Vasconcelos; ARAUJO, Wagner Junqueira. Editoras universitárias e a publicação de livros digitais no Brasil. In: SISPUB- Encontro de usuários de sistemas de publicação, 2017, Brasília. Anais [...]. Brasília: IBICT, 2017. Disponível em: http://eventos.ibict.br/index.php/sispub/SISPUB2017/paper/view/17. Acesso em: 18 nov. 2021.

ALVES, Rachel Cristina Vesu. Metadados editoriais e livreiros: algumas considerações e relações com os padrões de metadados do domínio bibliográfico. Informação \& Tecnologia, Marília/João Pessoa, v.5, n.2, 2018. Disponível em:

https://periodicos.ufpb.br/index.php/itec/article/view/44971. Acesso em: 06 jan. 2021.

ARAKAKI, A. C. S.; ARAKAKI, F. A. A. Dados e metadados: conceitos e relações. Ciência da Informação, [S. 1.], v. 49, n. 3, 2020. Disponível em:

http://revista.ibict.br/ciinf/article/view/5504. Acesso em: 28 jun. 2021.

BACA, Murtha. (ed.). Introduction to metadata. 3. ed. Los Angeles: Getty Publications, 2016. Disponível em: http://www.getty.edu/publications/intrometadata/metadata-matters/. Acesso em 01 jul 2021.

BUFREM, Leilah Santiago. Editoras universitárias no Brasil: uma crítica para a reformulação da prática. 2. ed. São Paulo: Edusp, 2015. 492p. ISBN 9788531415234

BUFREM, Leilah Santiago; GARCIA, Tânia Maria Braga. A editora universitária e o compromisso da universidade com as práticas de divulgação do conhecimento produzido. Em Questão, Porto Alegre, v. 20, n. 1, 2014. Disponível em: https://seer.ufrgs.br/EmQuestao/article/view/40816. Acesso em: 27 jun. 2020.

EDITEUR. ONIX for Books: Overview. Disponível em: https://www.editeur.org/83/Overview/. Acesso em: 11 jan. 2021.

EDITEUR. ONIX for books product information format: Introduction to ONIX 3.0. Londres, 2009-2019. 23p. Disponível em: 


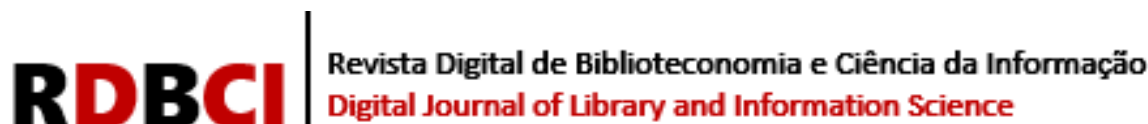

https://www.editeur.org/files/ONIX\%203/Introduction_to_ONIX_for_Books_3.0.7.pdf. Acesso em: 09 jan. 2021.

EDITORA UNICAMP. Homepage. Campinas, 2021, on-line. Disponível em: https://www.editoraunicamp.com.br/. Acesso em: 09 ago. 2021.

EDUEMG. Início. Belo Horizonte, 2021, on-line. Disponível em: http://eduemg.uemg.br/. Acesso em: 09 ago. 2021.

EDUFRO. Homepage. Porto Velho, 2021, on-line. Disponível em: https://edufro.unir.br/. Acesso em: 09 ago. 2021.

FUNDAÇÃO EDITORA UNESP. Quem somos. São Paulo, 2021, on-line. Disponível em: http://editoraunesp.com.br/quemsomos. Acesso em: 09 ago. 2021.

FACHIN, Gleisy. Mais sobre metadados. São Paulo: ABEU, 2020, on-line. Disponível em: https://www.abeu.org.br/mais-sobre-metadados/. Acesso em: 30 set. 2021.

GONSALVES, Elisa Pereira. Conversas sobre iniciação à pesquisa científica. 4. ed. Campinas: Editora Alínea, 2007. 96p. ISBN 9788575162064

MERCADOEDITORIAL.ORG. Home. Disponível em: https://www.mercadoeditorial.org/. Acesso em: 10 jan. 2021.

METABOOKS. Home. Disponível em: https://metabooks.com/. Acesso em: 10 jan. 2021.

POMERANTZ, Jeffrey. Metadata. Massachusetts: The MIT Press, 2015. 239p.

RAMALHO, Amanda. Os livros e as tecnologias: metadados, formatos e linguagens. In: ROSA, Flávia Goulart; ARGOLLO, Rita Virginia. (org.). Editoras universitárias: estratégias de gestão. São Paulo: ABEU, 2019. 233p. ISBN 9788560442034. Disponível em: https://arquivosbrasil.blob.core.windows.net/insulas/anexos/editoras-universitarias-miolointegral-versao-grafica.pdf. Acesso em: 30 set. 2021.

RAMALHO, Amanda; GUTIERRE, Jézio Hernani Bomfim. Editoras acadêmicas e metadados: por que se preocupar com isso? In: Rodas de Conversa ABEU, 29 out. 2020, São Paulo. Disponível em: https://www.youtube.com/watch?v=tIqYG8tuf5k. Acesso em: 17 dez. 2020.

SANTOS, Plácida Leopoldina Ventura Amorim da Costa; SIMIONATO, Ana Carolina; ARAKAKI, Felipe Augusto. Definição de metadados para recursos informacionais: apresentação da metodologia BEAM. Informação \& Informação, Londrina, v. 19, n. 1, p. 146-163, fev. 2014. ISSN 1981-8920. Disponível em: https://www.uel.br/revistas/uel/index.php/informacao/article/view/15251. Acesso em: 13 dez. 2021.

SAYÃO, Luís Fernando. Uma outra face dos metadados: informação para a gestão da preservação digital. Encontros Bibli, Florianópolis, v. 15, n. 30, 2010. Disponível em: https://www.redalyc.org/pdf/147/14716919002.pdf. Acesso em: 17 dez. 2020. 


\section{$\mathrm{RDBCI} \mid$}

SERRA, Liliana Giusti. A web semântica na gestão de livros digitais licenciados: uma proposta de modelo. 2019. 152f. Tese (Doutorado em Ciência da Informação) - Universidade Estadual Paulista "Julio de Mesquita Filho", Marília, 2019. Disponível em: https://repositorio.unesp.br/handle/11449/183526. Acesso em: 30 set. 2021.

SCIELO LIVROS. Disponibilidade e interoperabilidade. Disponível em: http://books.scielo.org/disponibilidade-e-interoperabilidade/. Acesso em: 11 jan. 2021.

ZENG, Marcia Lei; QIN, Jian. Metadata. 2. ed. Chicago: Neal-Schuman Publishers, 2016. 555p. ISBN 978155709655 


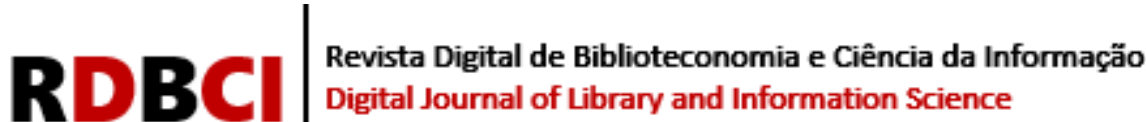

